\title{
BDSF Is the Predominant In-Planta Quorum-Sensing Signal Used During Xanthomonas campestris Infection and Pathogenesis in Chinese Cabbage
}

\author{
Abdelgader Abdeen Diab, ${ }^{1}$ Xue-Qiang Cao, ${ }^{1}$ Hui Chen, ${ }^{1}$ Kai Song, ${ }^{1}$ Lian Zhou, ${ }^{2}$ Bo Chen, ${ }^{1}$ and \\ Ya-Wen $\mathrm{He}^{1, \dagger}$ \\ ${ }^{1}$ State Key Laboratory of Microbial Metabolism, Joint International Research Laboratory of Metabolic \& Developmental \\ Sciences, School of Life Sciences and Biotechnology, Shanghai Jiao Tong University, Shanghai 200240, China; and \\ ${ }^{2}$ Zhiyuan Innovation Research Centre, Student Innovation Centre, Zhiyuan College, Shanghai Jiao Tong University
}

Accepted 15 August 2018.

\begin{abstract}
Xanthomonas campestris pv. campestris uses the diffusible signal factor (DSF) family of quorum-sensing (QS) signals to coordinate virulence and adaptation. DSF family signals have been well-characterized using laboratory-based cell cultures. The in-planta QS signal used during $X$. campestris pv. campestris infection remains unclear. To achieve this goal, we first mimic in-planta $X$. campestris pv. campestris growth conditions by supplementing the previously developed XYS medium with cabbage hydrolysate and found that the dominant signal produced in these conditions was BDSF. Secondly, by using XYS medium supplemented with diverse plant-derived compounds, we examined the effects of diverse plant-derived compounds on the biosynthesis of DSF family signals. Several compounds were found to promote biosynthesis of BDSF. Finally, using an $X$. campestris pv. campestris $\Delta r p f B-C h i n e s e$ cabbage infection model and an ultra-performance liquid chromatographic-time of flight-mass spectrometry-based assay, BDSF was found to comprise $>70 \%$ of the DSF family signals present in infected cabbage tissue. BDSF at a concentration of $2.0 \mu \mathrm{M}$ induced both protease activity and engXCA expression. This is the first report to directly show that $B D S F$ is the predominant in-planta QS signal used during $X$. campestris pv. campestris infection. It provides a better understanding of the molecular interactions between $X$. campestris pv. campestris and its cruciferous hosts and also provides the logical target for designing strategies to counteract BDSF signaling and, thus, infection. Further studies are needed to get an exact idea about the DSF production dynamics of the wild-type strain inside the plant.
\end{abstract}

Bacteria are able to sense and respond to changes in their populations by communicating with small signal molecules, a

Abdelgader Abdeen Diab and Xue-Qiang Cao contributed equally.

${ }^{\dagger}$ Corresponding author: Ya-Wen He; E-mail: yawenhe@sjtu.edu.cn

Funding: This work was financially supported by research grants from the National Natural Science Foundation of China (No. 31471743 and No. 31772121 to Ya-Wen He) and National Key Research and Development Program of China (2016YFE0101000 to Lian Zhou).

The $\boldsymbol{e}$-Xtra logo stands for "electronic extra" and indicates that seven supplementary figures and two supplementary tables are published online.

(c) 2019 The American Phytopathological Society mechanism known as quorum sensing (QS). The diffusible signal factor (DSF) family represents a new type of QS signal molecule that is found in diverse gram-negative bacteria, including Xanthomonas campestris, Xylella fastidiosa, Burkholderia cepacia, and Pseudomonas aeruginosa (Deng et al. 2011; He and Zhang 2008). DSF family signals are cis-2unsaturated fatty acids, containing fatty acid carbon chains with variations in length, double-bond configuration, and side-chain composition (Zhou et al. 2017). DSF family signals have been shown to regulate motility, biofilm formation, iron uptake, exopolysaccharide (EPS) and extracellular enzyme production, and virulence in these bacterial pathogens (Deng et al. 2011; He and Zhang 2008). Recently, the DSF family signals were found to provide a fitness advantage in mixed culture (Dean et al. 2015; Deng et al. 2016; Han et al. 2015). Pathogen-derived DSF signal elicits host plant innate immunity (Kakkar et al. 2015). These new findings demonstrate that DSF family signals are not only important for communication within a homogeneous bacterial population but, also, function in the areas of interspecies and interkingdom communication (Zhou et al. 2017).

The crucifer pathogen Xanthomonas campestris pv. campestris is one of the model bacteria used in studying DSF family signaling. $X$. campestris pv. campestris contains a rpf gene cluster that encodes the key DSF signaling components RpfB, RpfF, RpfC, and RpfG (Slater et al. 2000; Tang et al. 1991). $\mathrm{RpfF}$ is a key enzyme required for DSF biosynthesis, whereas RpfC and RpfG constitute a two-component regulatory system involved in DSF signal perception and transduction (Cai et al. 2017; He et al. 2006a; Slater et al. 2000). The activated RpfG has phosphodiesterase activity and is able to degrade cyclic diGMP (c-di-GMP). C-di-GMP is an inhibitory ligand of the transcription factor Clp (Tao et al. 2010). The de-repressed Clp further regulates the expression of several hundreds of genes, including those virulence factor genes (He et al. 2007; Tao et al. 2010). RpfB has fatty acyl-CoA ligase activity and is involved in the turnover of the DSF family signals in $X$. campestris pv. campestris (Wang et al. 2016; Zhou et al. 2015).

In $X$. campestris pv. campestris DSF biosynthesis is negatively controlled by RpfC via a mechanism involving RpfCRpfF interactions (He and Zhang 2008; He et al. 2006a). RpfF has both dehydratase and thioesterase activities and uses 3-hydroxyacyl-ACP as a direct substrate to synthesize DSF family signals. The substrate 3-hydroxyacyl-ACP is further derived from the classic fatty acid synthesis pathway $(\mathrm{Hu}$ et al. 2018; Zhou et al. 2015). Interestingly, several bacterial species produce one or more DSF family signals, such as DSF 
(cis-11-methyl-2-dodecenoic acid), BDSF (cis-2-dodecenoic acid), CDSF (cis-11-methyldodeca-2,5-dienoic acid), IDSF (cis-10-methyl-2-dodecenoic acid), cis-9-methyl-2-decenoic acid, and cis-2-undecenoic acid (Deng et al. 2010; He et al. 2010; Zhou et al. 2015; Deng et al. 2016). The relative proportions of these signals are influenced by the composition of the culture medium in which the bacteria are grown. Zhou et al. (2015) revealed that $X$. campestris pv. campestris produces mainly BDSF in the media containing different carbohydrates as carbon sources. Methyl substitutions in DSF originate from leucine and valine and from isoleucine in IDSF (Zhou et al. 2015). RpfF could use multiple types of acyl-ACP precursors for the synthesis of DSF family signals (Zhou et al. 2015).

$X$. campestris pv. campestris is a vascular pathogen and normally gains entry to the plant via leaf margin hydathodes, stomata, or wounds (Hugouvieux et al. 1998). Once inside the plant, $X$. campestris pv. campestris uses plant-derived nutrients to multiply and form microcolonies, while producing a range of extracellular enzymes that degrade plant cells. X. campestris pv. campestris then disperses and colonizes the host plant vascular system, in which it produces extracellular enzymes and the extracellular polysaccharide called EPS or xanthan gum (Onsando 1992; Williams 1980). During all stages of disease development, QS mechanisms are importantt for the production of extracellular enzymes and other virulence factors (He and Zhang 2008). However, all studies on Xanthomonas QS to date have been conducted in laboratory-based cell cultures and very little is known about the QS process during host plant infection. This study is aimed to determine the in-planta QS signals used by Xanthomonas spp. during the infection process.

\section{RESULTS}

\section{The strains for investigating in-planta QS signals in this study.}

During growth in culture, $X$. campestris pv. campestris wildtype levels of DSF and BDSF are extremely low, making them very difficult to identify and characterize (Wang et al. 2004). This is because the synthase RpfF is repressed by RpfC (Cheng et al. 2010; He et al. 2006a) and, also, because during late growth stages, RpfB is induced and degrades DSF signals (Zhou et al. 2015). To overcome these problems, the $r p f C$ and $r p f B$ doubledeletion strain $\triangle r p f C \Delta r p f B$, which constitutively produces DSF and BDSF at high levels (Zhou et al. 2015), was used to conveniently and accurately monitor the DSF family signals produced in culture. The use of this strain was further supported by our previous finding that RpfB has the same activity against DSF and BDSF in vivo. The ratios of DSF and BDSF in $r p f B$ deletion or overexpression strains were similar to that of the wild-type strain (Wang et al. 2016; Zhou et al. 2015). Moreover, since the $\Delta r p f B$ strain was previously shown to be more virulent in Chinese radish and to produce higher levels of DSF and BDSF than the wild-type strain (Zhou et al. 2015), it greatly facilitated the establishment of the $X$. campestris pv. campestris-cabbage infection and the detection of DSF family signals in the infected cabbage tissue.

\section{Biosynthesis of DSF family signals \\ in the presence of plant hydrolysate.}

The nutrients available for $X$. campestris pv. campestris growth and development in planta are not likely to be solitary but, instead, a mixture of multiple components. To mimic these inplanta growth conditions, hydrolysate was extracted from Chinese cabbage, using previously described methods (Xu et al. 2010). The cabbage hydrolysate was then added to $\triangle r p f C \Delta r p f B$ XY (XOLN salts with $0.02 \%$ yeast extract) or XYS (XY with $0.2 \%$ sucrose) medium culture at a final concentration of either 1 or $2 \%$. The levels of DSF and BDSF in the cultures were determined and were then expressed as concentrations of micromoles per $10^{9}$ cells, following previously described methods (Zhou et al. 2015). In XY medium, strain $\triangle r p f C \Delta r p f B$ produced both BDSF $\left(0.06 \times 10^{-3} \mu \mathrm{mol} / 10^{9}\right.$ cells $)$ and DSF $\left(0.11 \times 10^{-3}\right.$ $\mu \mathrm{mol} / 10^{9}$ cells) (Fig. 1B). The addition of 1 or $2 \%$ plant hydrolysate to medium XY increased bacterial growth from 20.0 to $40 \%$ (Fig. 1A). In the presence of plant hydrolysate, the BDSF levels of the $\triangle r p f C \triangle r p f B$ cultures were $0.26 \times 10^{-3} \mu \mathrm{mol} / 10^{9}$ cells $\left(1 \%\right.$ hydrolysate) and $0.38 \times 10^{-3} \mu \mathrm{mol} / 10^{9}$ cells $(2 \%$ hydrolysate), which are 3.3- and 5.3-fold increases over that of XY culture without hydrolysate, respectively (Fig. 1B). The DSF levels in the presence of cabbage hydrolysate were $0.15 \times 10^{-3}$ $\mu \mathrm{mol} / 10^{9}$ cells $\left(1 \%\right.$ hydrolysate) and $0.22 \times 10^{-3} \mu \mathrm{mol} / 10^{9}$ cells ( $2 \%$ hydrolysate), which are $0.4-$ and 1.0 -fold increases over that of the XY culture without hydrolysate, respectively (Fig. 1B).

In XYS medium, strain $\triangle r p f C \Delta r p f B$ produces more $\operatorname{BDSF}\left(0.47 \times 10^{-3} \mu \mathrm{mol} / 10^{9}\right.$ cells $)$ than DSF $\left(0.07 \times 10^{-3}\right.$ $\mu \mathrm{mol} / 10^{9}$ cells) (Fig. 1D). In this medium, the addition of plant hydrolysate to the $\triangle r p f C \triangle r p f B$ culture had little effect on bacterial growth (Fig. 1C); however, BDSF levels were significantly increased. BDSF levels of $\triangle r p f C \Delta r p f B$ cultures with the addition of cabbage hydrolysate reached $1.0 \times 10^{-3}$ $\mu \mathrm{mol} / 10^{9}$ cells ( $1 \%$ hydrolysate) and $1.6 \times 10^{-3} \mu \mathrm{mol} / 10^{9}$ cells ( $2 \%$ hydrolysate), increases of 1.1 and 2.4 -fold, respectively. In contrast, DSF levels observed in XYS cultures supplemented with cabbage hydrolysate were still quite low, at $0.11 \times 10^{-3}$ $\mu \mathrm{mol} / 10^{9}$ cells ( $1 \%$ hydrolysate) and $0.18 \times 10^{-3} \mu \mathrm{mol} / 10^{9}$ cells (2\% hydrolysate) (Fig. 1D).

Deng et al. (2015) conducted similar assay in X. campestris pv. campestris and found that addition of crucifer plant juice or ethanol extract to $X$. campestris pv. campestris growth media significantly increased DSF family signal production. No dominant QS signal was reported. To further explore the potential mechanisms underlying the roles of a range of plant-derived compounds on the biosynthesis of DSF family, signals were investigated in the following sections.

\section{The effects of non-branched chain amino acids on the biosynthesis of DSF family signals.}

Plants are a rich source of amino acids that perform various prominent roles and functions for the plant (Hildebrandt et al. 2015) and also provide important nutrition for $X$. campestris $\mathrm{pv}$. campestris growth in planta. Our previous results showed that the addition of the branched-chain amino acids valine and leucine or isoleucine to $X$. campestris pv. campestris $\triangle r p f C \Delta r p f B$ in XYS medium promoted DSF or IDSF biosynthesis, respectively (Zhou et al. 2015). In this study, we investigated the effects of 15 non-branched chain amino acids on the biosynthesis of the DSF family. Exogenous addition of these non-branched chain amino acids to XYS medium at a final concentration of 0.1 or $0.5 \mathrm{mM}$ had little effect on bacterial growth. The $\Delta r p f C \Delta r p f B$ strain grew to a maximum optical density at $600 \mathrm{~nm}\left(\mathrm{OD}_{600}\right)$ of 1.2 at $24 \mathrm{~h}$ after inoculation, regardless of amino acid additions to culture medium (Supplementary Figs. S1, S2, S3, and S4). Four amino acids, cysteine, glutamate, phenylalanine, and histidine, at concentrations of either 0.1 or $0.5 \mathrm{mM}$, significantly increased BDSF production (Fig. 2), and glutamate significantly increased DSF levels (Fig. 3). The effect of glutamate on DSF biosynthesis was less significant than that of leucine and valine (Fig. 3). In contrast, addition of the 15 non-branched chain amino acids to XYS medium had little effect on IDSF biosynthesis (Supplementary Fig. S5).

To further investigate how these non-branched chain amino acids affect BDSF or DSF biosynthesis, the expression level of RpfF, a key enzyme involved in DSF biosynthesis, was investigated in the presence of the above-mentioned four amino 

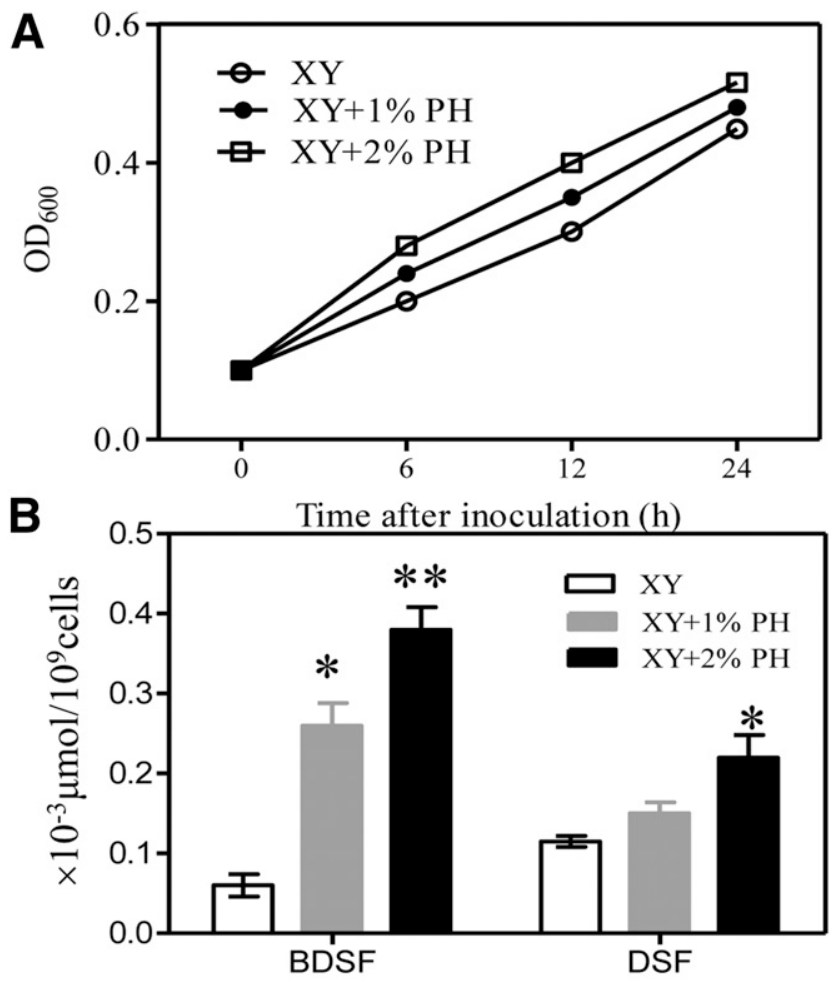

C

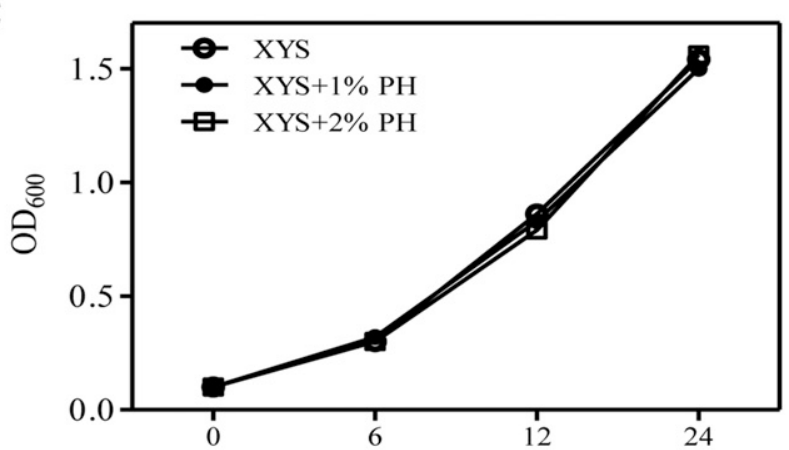

D

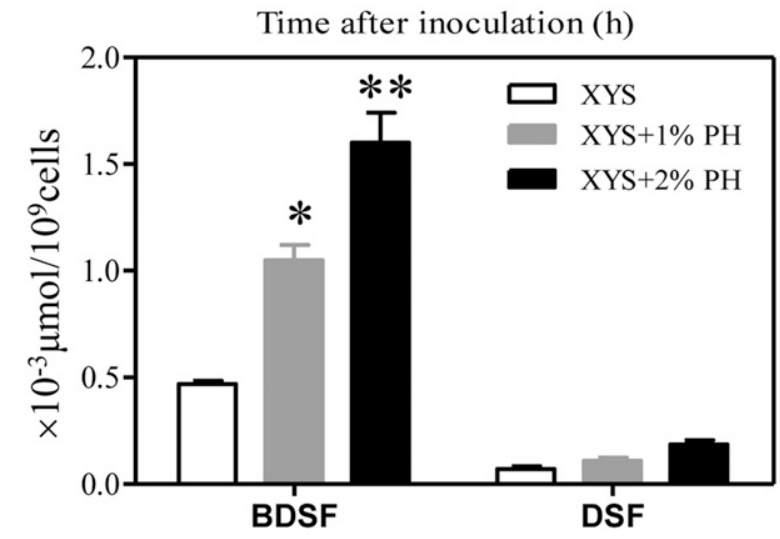

Fig. 1. Effects of plant hydrolysate on diffusible signal factor (DSF) and BDSF biosynthesis. A, Growth curve of Xanthomonas campestris pv. campestris in XY (XOLN salts with $0.02 \%$ yeast extract) medium. B, DSF and BDSF production of the strain $\Delta r p f C \Delta r p f B$ in XY medium supplemented with cabbage hydrolysate at concentrations of either 1 or $2 \%$. C, Growth curve of $X$. campestris pv. campestris in XYS (XY with $0.2 \%$ sucrose) medium. D, DSF and BDSF level of the strain $\triangle r p f C \Delta r p f B$ observed in XYS medium supplemented with cabbage hydrolysate at concentrations of either 1 or $2 \%$. Each experiment was repeated twice, the data shown are the average of three replicates and error bars represent standard deviations. Statistically significant differences with respect to the nonamended XY medium are indicated by one asterisk $(P \leq 0.05)$. acids. Western blotting analysis showed that none of these amino acids had a significant effect on RpfF levels, suggesting that these four amino acids probably promote BDSF biosynthesis in another manner, such as through metabolic processes.

The effects of branched-chain $\alpha$-ketoacids and carboxylic acids on the biosynthesis of DSF family signals.

In bacteria, the branched-chain fatty acids are synthesized from branched-chain acyl-CoA with malonyl-CoA as the chain extender (Kaneda 1991). The branched-chain acyl-CoA can be synthesized from the branched-chain $\alpha$-ketoacids, including $\alpha$-ketoisocaproic acid (KIC), $\alpha$-ketoisovaleric acid (KIV), and $\alpha$-keto- $\beta$-methylvaleric acid (KMV). These $\alpha$-ketoacids are derived from the catabolism of the branched-chain amino acids, i.e., leucine, valine, and isoleucine (Beck 2005). Alternatively, the exogenously supplied short-chain carboxylic acids, including isobutyric acid (IBA), isovaleric acid (IVA), and 2methylbutyric acid (2MBA), can be used for branched-chain acyl-CoA biosynthesis (Ward et al. 1999). To investigate whether these $\alpha$-ketoacids and carboxylic acids influence the biosynthesis of DSF family signals, they were separately added to $X$. campestris pv. campestris $\triangle r p f C \Delta r p f B$ cultures at a final concentration of $0.01,0.1$, or $0.5 \mathrm{mM}$. Although the exogenous addition of three $\alpha$-ketoacids had no significant effects on the growth of strain $\Delta r p f C \Delta r p f \mathrm{~B}$, analysis of the culture supernatants $24 \mathrm{~h}$ after inoculation revealed that the addition of either KIC or KIV increased DSF levels whereas the addition of KMV increased IDSF levels (Fig. 4).

Although exogenous addition of $0.1 \mathrm{mM}$ carboxylic acid to the $\triangle r p f C \Delta r p f B$ culture had no significant effect on bacterial growth, $0.5 \mathrm{mM}$ carboxylic acid did significantly inhibit $X$. campestris pv. campestris growth. Regardless, analysis of the culture supernatants at $24 \mathrm{~h}$ after inoculation revealed that the three carboxylic acids had little effect on the biosynthesis of DSF family signals (Supplementary Figs. S6).

The effects of plant-derived organic acids on the biosynthesis of DSF family signals.

Shikimic acid, citric acid, malic acid, and succinic acid are organic acids that are important in the basic metabolism of all organisms. To determine the potential effects of these organic acids on the biosynthesis of DSF family signals, $\triangle r p f C \Delta r p f B$ cultures were supplemented with each of the four organic acids, separately, at final concentrations of $0.01,0.1$, or $0.5 \mathrm{mM}$. Analysis of the results revealed that these organic acids had no significant effect on the biosynthesis of DSF family signals (Supplementary Fig. S7).

\section{The effects of plant hormones}

on the biosynthesis of DSF family signals.

Plant hormones are signal molecules produced within the plant to regulate growth and development. In order to understand their effects on the biosynthesis of DSF family signals, abscisic acid (ABA), gibberellic acid (GA3), indol-3-acetic acid (IAA), epibrassinolide (EBL), jasmonate (JAS), and salicylic acid (SA) were separately added to $\triangle r p f C \Delta r p f B$ cultures at final concentrations of either 0.01 or $0.10 \mathrm{mM}$. Although these phytohormones had little effect on bacterial growth (Fig. $5 \mathrm{~A}$ ), analysis of the $\triangle r p f C \Delta r p f B$ cultures $24 \mathrm{~h}$ after inoculation showed that the addition of $\mathrm{ABA}$ and GA3 significantly increased DSF levels and decreased BDSF levels (Fig. 5B and C). In contrast, the addition of SA significantly increased BDSF levels and decreased DSF levels (Fig. 5B and C). The other plant hormones had little effect on DSF and BDSF biosynthesis. Furthermore, Western blotting analysis showed that the addition of GA3 and SA had little effect on RpfF levels, but the addition of ABA at a concentration of $100 \mu \mathrm{M}$ significantly decreased RpfF levels (Fig. 5D). 
The effects of plant-derived phenolic compounds on the biosynthesis of DSF family signals.

Naturally occurring phenolic compounds are found at high levels in plants and play a major role in plant reproduction and growth as well as defense against pathogens (Báidez et al. 2007; Huang et al. 2010). To determine the possible role of phenolic compounds in DSF family signal biosynthesis, strain $\Delta r p f C \Delta r p f B$ was grown for $24 \mathrm{~h}$ in XYS medium supplemented with 3-hydroxybenzoic acid (3-HBA), 4-HBA, vallinic acid, gallic acid, trans-2 hydroxycinnamic acid (2-HCA), 3,4dihydroxybenzoic acid, ferulic acid, or caffeic acid at final concentrations of 0.1 or $0.5 \mathrm{mM}$. The addition of these

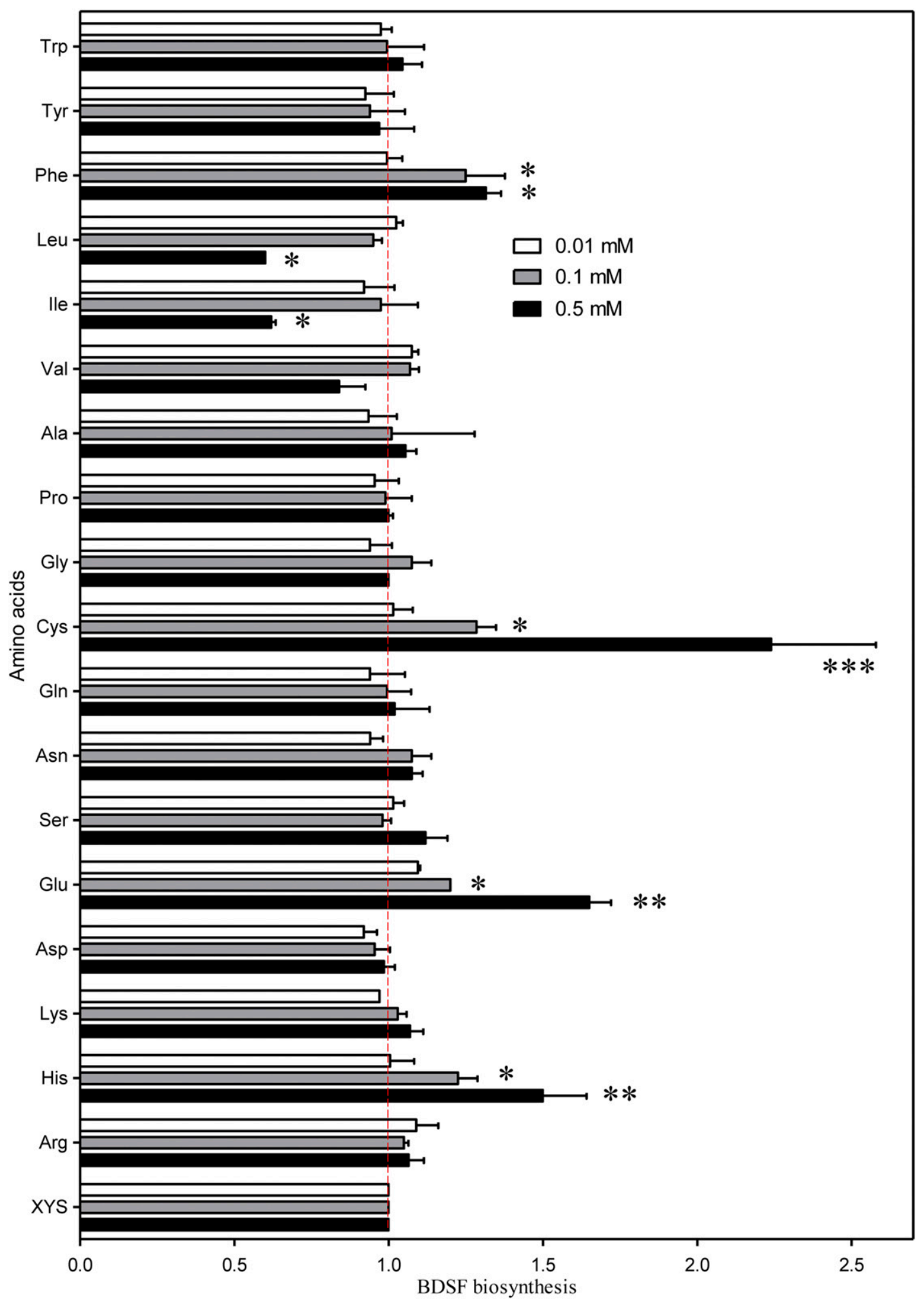

Fig. 2. Diffusible signal factor BDSF biosynthesis by Xanthomonas campestris pv. campestris $\triangle r p f B \Delta r p f C$ in the presence of different amino acids. Strain $\Delta r p f C \Delta r p f B$ was grown in XYS (XOLN salts with $0.02 \%$ yeast extract with $0.2 \%$ sucrose) medium containing 0.1 or $0.5 \mathrm{mM}$ amino acids at $30^{\circ} \mathrm{C}$ for $24 \mathrm{~h}$ Each bar represents the average of three independent experiments and error bars represent standard deviations. Statistically significant differences with respect to the nonamended XYS medium are indicated by one or two asterisks $(P \leq 0.05$ or 0.01 , respectively). 
compounds to XYS culture medium had little effect on bacterial growth (Fig. 6A). However, the addition of either 4-HBA or 2-HCA significantly increased BDSF levels in the cultures (Fig. 6B and C), and 3-HBA at a concentration of $0.5 \mathrm{mM}$ significantly decreased DSF levels. None of the other phenolic acids had significant effects on the biosynthesis of DSF family signals (Fig. 6B and C). Furthermore, Western blotting analysis showed that the addition of 2-HCA significantly increased levels of RpfF, although the addition of 4-HBA had little effect on RpfF levels (Fig. 6D).

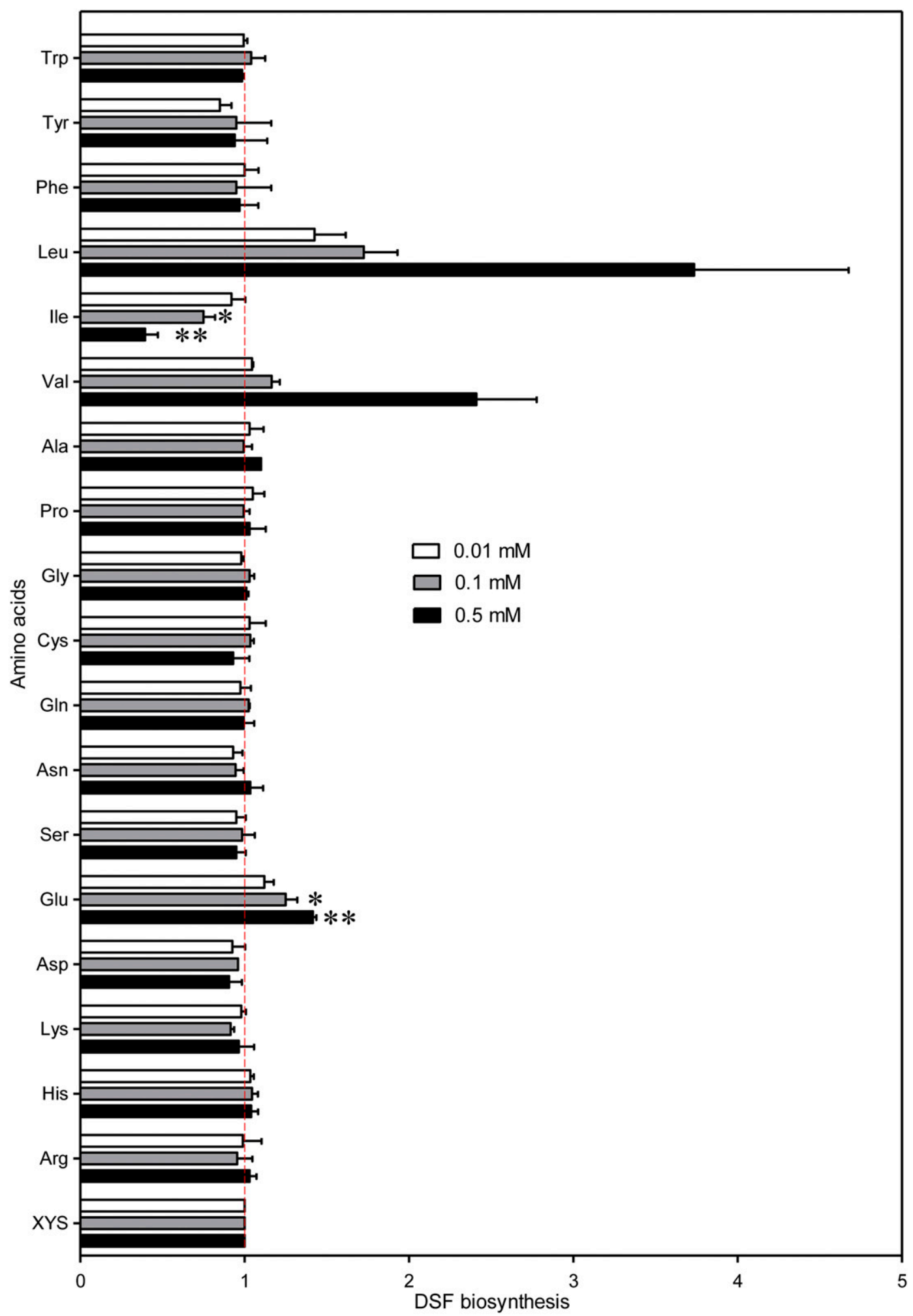

Fig. 3. Diffusible signal factor (DSF) biosynthesis by strain $\triangle r p f B \Delta r p f C$ in the presence of different amino acids. The $\Delta r p f C \Delta r p f B$ strain was grown in $X Y S$ (XOLN salts with $0.02 \%$ yeast extract with $0.2 \%$ sucrose) media containing 0.1 or $0.5 \mathrm{mM}$ amino acids at $30^{\circ} \mathrm{C}$ for $24 \mathrm{~h}$. Each bar represents the average of three independent experiments and error bars represent standard deviations. Statistically significant differences with respect to the nonamended XYS medium are indicated by one or two asterisks $(P \leq 0.05$ or 0.01 , respectively). 
DSF family signals

in $X$. campestris pv. campestris-infected cabbage.

To further understand the QS signals utilized by $X$. campestris pv. campestris in planta during the infection process, we used an $X$. campestris pv. campestris $\Delta r p f B$ strain to infect Chinese cabbage, because the $r p f B$ mutant strain is more virulent on Chinese radish and produces higher levels of DSF family signals than the wild-type strain (Zhou et al. 2015). At different stages of infection, the infected cabbages were collected to monitor bacterial growth by counting the
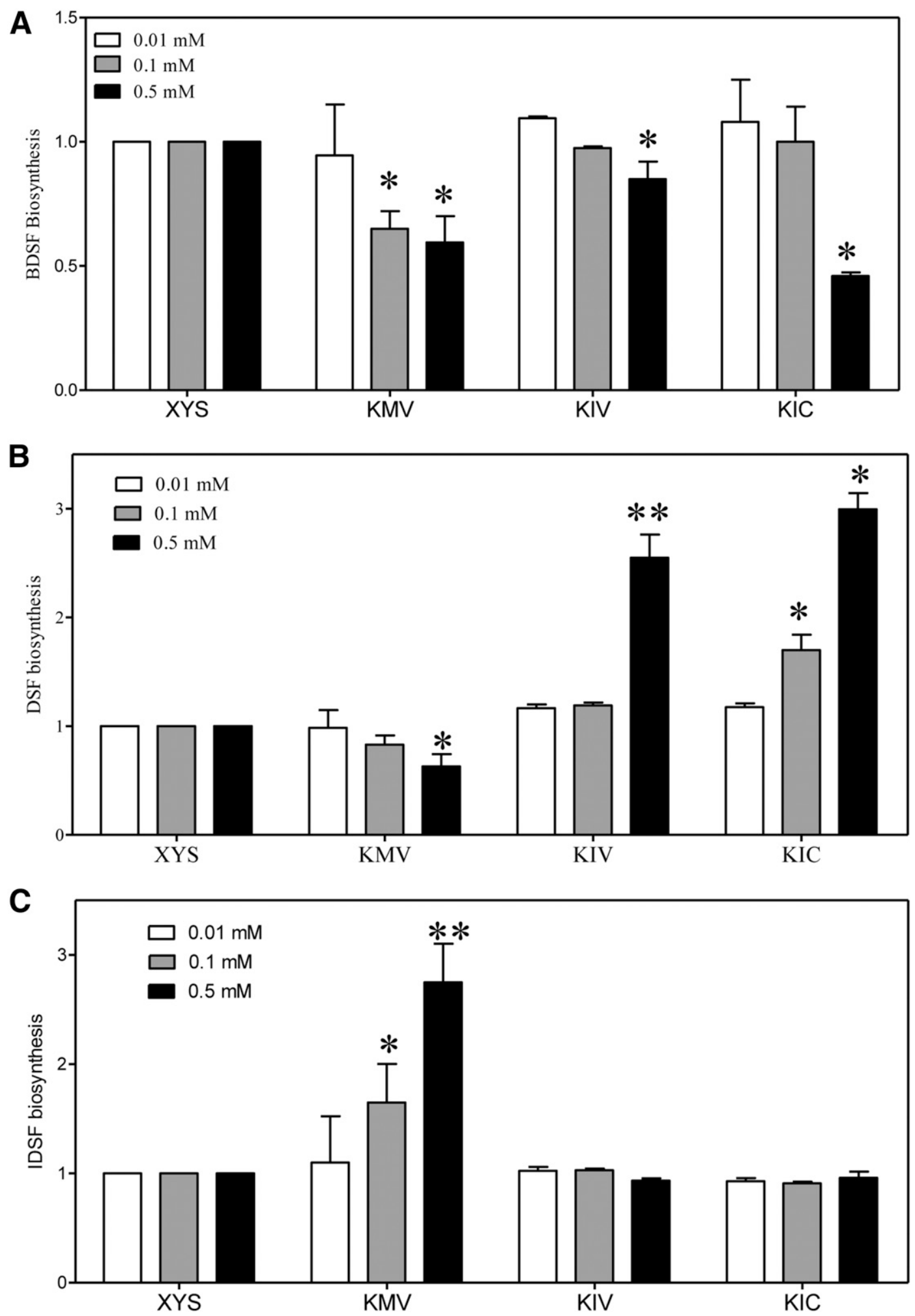

Fig. 4. Diffusible signal factor (DSF) family signal biosynthesis by strain $\triangle r p f B \Delta r p f C$ in the presence of different $\alpha$-ketoacids. A, BDSF biosynthesis. B, DSF biosynthesis. C, IDSF biosynthesis. X. campestris pv. campestris $\Delta r p f C \Delta r p f B$ was grown in XYS (XOLN salts with $0.02 \%$ yeast extract with $0.2 \%$ sucrose) medium containing $\alpha$-keto acids at a concentration of either 0.1 or $0.5 \mathrm{mM}$ at $30^{\circ} \mathrm{C}$ for $24 \mathrm{~h}$. Each bar represents the average of three independent experiments and error bars represent standard deviations. Statistically significant differences with respect to the nonamended XYS medium are indicated by one or two asterisks $(P \leq 0.05$ or 0.01 , respectively). KMV $=\alpha$-keto- $\beta$-methylvaleric acid, KIV $=\alpha$-ketoisovaleric acid, and KIC $=\alpha$-ketoisocaproic acid. 
colony number per gram of fresh weight and to extract DSF family signals. Methods for extracting and purifying DSF family signals from infected cabbage plants were established, and the quantitative analysis of DSF family signals was optimized based on latest description by Zhou et al. (2018).

Strain $\triangle r p f B$ effectively established infections in Chinese cabbage plants and black rot disease was observed
A

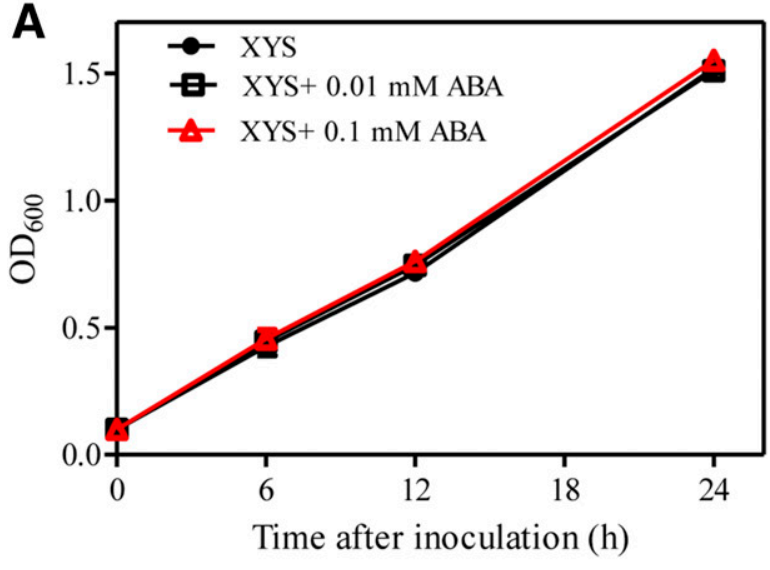

D 0

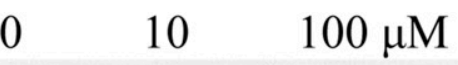

ABA

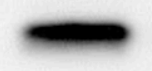

54

56

25

GA3

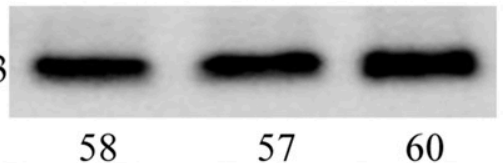

SA

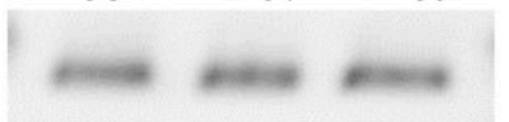

B
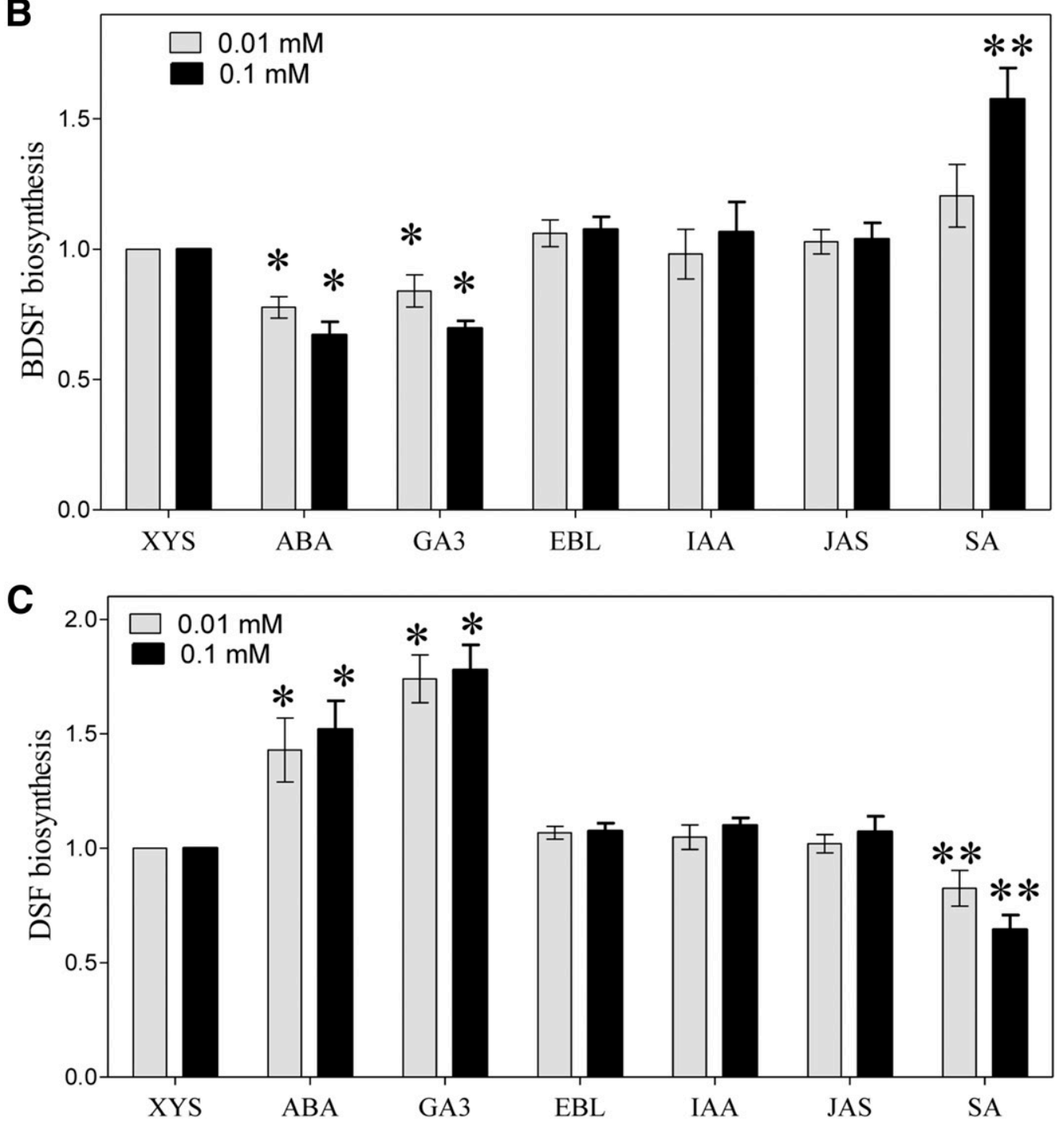

Fig. 5. Diffusible signal factor (DSF) family signal biosynthesis by strain $\triangle r p f B \Delta r p f C$ in the presence of different plant hormones. A, Bacterial growth curves of $X$. campestris pv. campestris strains. B, BDSF biosynthesis. C, DSF biosynthesis. D, Western blotting analysis showing the effects of abscisic acid (ABA), gibberellic acid (GA3), and salicylic acid (SA) on RpfF expression. Xanthomonas campestris pv. campestris $\Delta r p f C \Delta r p f B$ was grown in XYS (XOLN salts with $0.02 \%$ yeast extract with $0.2 \%$ sucrose) medium containing plant hormones at a concentration of either 0.01 or $0.1 \mathrm{mM}$ at $30^{\circ} \mathrm{C}$ for $24 \mathrm{~h}$. Each bar represents an average of three independent experiments and error bars represent standard deviations. Statistically significant differences with respect to the nonamended XYS medium are indicated by one or two asterisks $(P \leq 0.05$ or 0.01 , respectively). IAA $=$ indol-3-acetic acid, $\mathrm{EBL}=$ epibrassinolide, and JAS $=$ jasmonate The numbers indicate the Western blotting signal intensities of RpfF as measured using ImageJ software. 
2 weeks after inoculation (Fig. 7A). The average number of $X$. campestris pv. campestris cells inside the infected cabbage were 17.1 per gram of fresh weight (FW) (first week), 65.4 per gram of FW (second week), and 86.5 per gram of FW (third week), respectively (Fig. 7C). No DSF or BDSF was detectable in the infected tissues 1 week after inoculation (Fig. 7C). The levels of DSF and BDSF at 2 to 3 weeks after inoculation reached 0.065 and $0.142 \mathrm{pmol}$ per gram of $\mathrm{FW}$, respectively
A

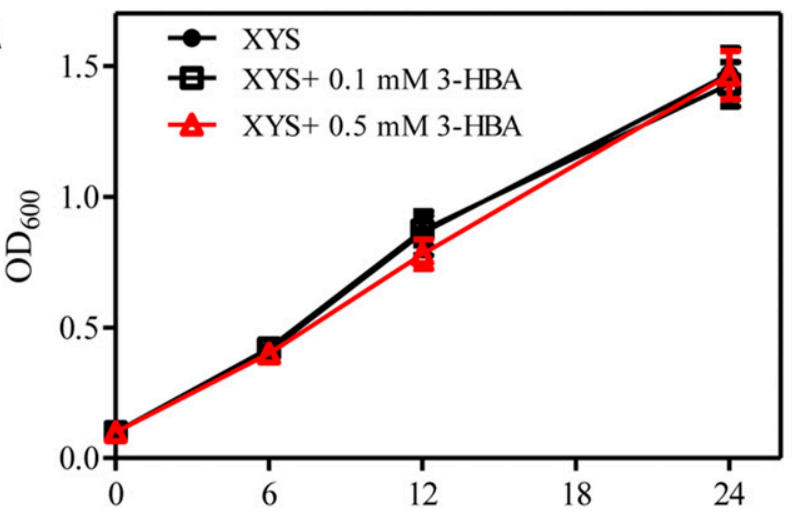

D

\section{2-HCA}

0.1

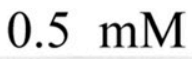

2-HCA

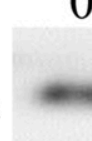

0

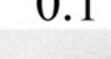

B

Time after inoculation (h)
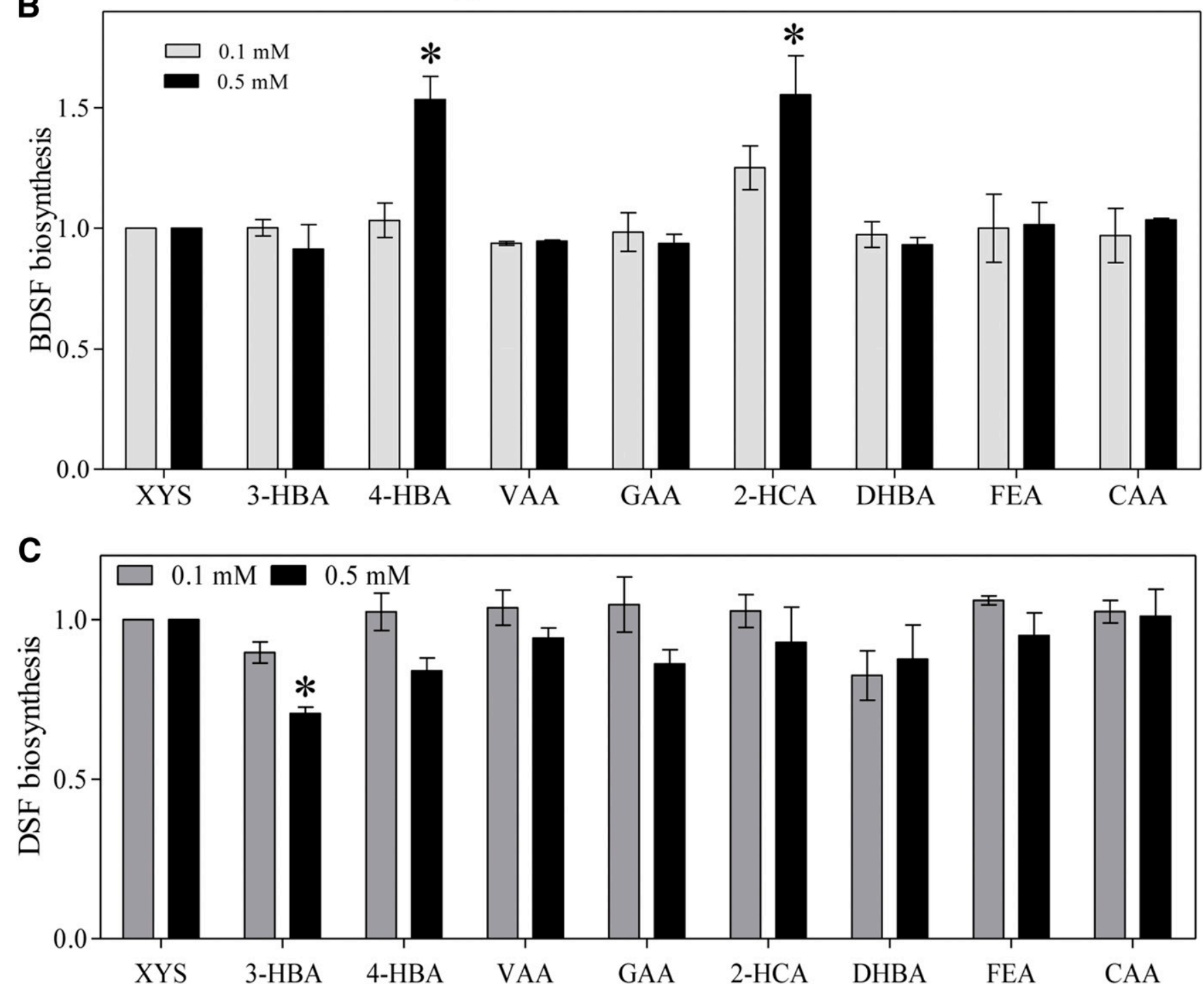

Fig. 6. Diffusible signal factor (DSF) family signal biosynthesis by strain $\Delta r p f B \Delta r p f C$ in the presence of different plant-derived phenolics. A, Growth curves of $X$. campestris pv. campestris strains. B, BDSF biosynthesis. C, DSF biosynthesis. X. campestris pv. campestris $\Delta$ rpfC $\Delta$ rpfB was grown in XYS (XOLN salts with $0.02 \%$ yeast extract with $0.2 \%$ sucrose) medium containing plant-derived phenolics at concentrations of either 0.1 or $0.5 \mathrm{mM}$ at $30^{\circ} \mathrm{C}$ for $24 \mathrm{~h}$. Each bar represents the average of three independent experiments and error bars represent standard deviations. Statistically significant differences with respect to the nonamended XYS medium are indicated by one asterisk $(P \leq 0.05)$. 3-HBA $=3$-hydroxybenzoic acid, 4-HBA $=4$-hydroxybenzoic acid, VAA $=$ vallinic acid, GAA = gallic acid, 2-HCA = trans-2 hydroxycinnamic acid, DHBA = 3,4-dihydroxybenzoic acid, FEA = ferulic acid, and CAA = caffeic acid. The numbers indicate the Western blotting signal intensities of RpfF as measured using ImageJ software. 
(Fig. 7C). Two major DSF family signals, BDSF and DSF were present in the infected cabbage tissue 2 weeks after inoculation (Fig. 7B and C). BDSF comprised $73.3 \%$ of the DSF family signals, and DSF was $26.7 \%$ of the total (Fig. 7C). In the infected cabbage tissue 3 weeks after inoculation, DSF and BDSF comprised 19.3 and $80.7 \%$ of the DSF family signals, respectively (Fig. 7C). No DSF family signals were detected from the phosphate buffered saline (PBS)-treated cabbage (data not shown).

\section{BDSF induces endoglucanase gene expression} and protease activity in $X$. campestris pv. campestris.

To further confirm that BDSF is a functional QS signal controlling virulence gene expression in $X$. campestris pv. campestris, it was added to BDSF-deficient $r p f F$ mutant cultures at final concentrations ranging from 0.1 to $2.0 \mu \mathrm{M}$. After $24 \mathrm{~h}$ of growth, protease activity and engXCA expression levels were compared with those of the wild-type strain. Exogenous addition of BDSF at 0.1 or $0.5 \mu \mathrm{M}$ had little effect on engXCA expression and protease activity (data not shown). However, the addition of BDSF at $1.0 \mu \mathrm{M}$ partially restored the protease activity and engXCA expression of the rpfF mutant to wild-type levels and addition of BDSF at $2.0 \mu \mathrm{M}$ fully restored these traits (Fig. 8A and B).

DSF is commonly used in $X$. campestris pv. campestris QS studies, since it was the first identified member of the DSF family and is the major QS signal produced in rich medium (Wang et al. 2004; Zhou et al. 2015). In this study, we further compared the inductive activity of BDSF and DSF at 1.0 and $2.0 \mu \mathrm{M}$ in the $\triangle r p f F$ culture. The protease-inducing activity of BDSF at a $1.0 \mu \mathrm{M}$ concentration was approximately $55 \%$ that of DSF at $1.0 \mu \mathrm{M}$; however, BDSF at a concentration of $2.0 \mu \mathrm{M}$ had an effect comparable to that of DSF at $2.0 \mu \mathrm{M}$ (Fig. 8C). Furthermore, the addition of BDSF at a concentration of $2.0 \mu \mathrm{M}$ to the strain $\triangle r p f F \Delta r p f C$ had no effect on protease activity (Fig. $8 \mathrm{C}$ ), suggesting that BDSF signaling may also be mediated by the receptor RpfC.

\section{DISCUSSION}

To successfully infect a plant, a pathogen must evolve the ability to utilize plant nutrients, establish, and disperse, and, at the same time, neutralize the host plant defenses. In order to study the in-planta QS signals synthesized by $X$. campestris pv. campestris during host infection, we developed three strategies that involved two $X$. campestris pv. campestris strains, $\Delta r p f B$ and $\Delta r p f B \Delta r p f C$. We first mimic in-planta $X$. campestris pv. campestris growth conditions by supplementing the previously developed XYS or XY medium with cabbage hydrolysate and found that the dominant signal produced in these conditions was BDSF. We then examined the effects of a range of specific plant-derived compounds on the biosynthesis of DSF family QS signals. Finally, we used an $X$. campestris pv. campestris $\Delta r p f B$ strain to infect Chinese cabbage and analyzed the exact composition of DSF family signals produced in infected cabbage.

\section{$X$. campestris pv. campestris uses diverse plant-derived compounds to promote BDSF biosynthesis.}

Amino acids are abundant plant constituents and can be found at various concentrations in plants. Glutamic acid and aspartic acid are the most abundant amino acids in plants (Kumar et al. 2017). During the late stages of disease development, $X$. campestris pv. campestris is normally restricted to the xylem vessels of infected plants. Xylem fluid contains carbohydrates, inorganic ions, and organic substances such as amino acids (Satoh 2006). X. campestris pv. campestris cells are, therefore, able to use many of these nutrients for growth and multiplication (Akimoto-Tomiyama et al. 2014). Our previous results showed that the addition of carbohydrates to $X$. campestris pv. campestris culture medium promotes BDSF biosynthesis, whereas the addition of the branched-chain amino acids leucine and valine or isoleucine leads to DSF or IDSF biosynthesis, respectively (Zhou et al. 2015). The present study showed that the addition of the non-branched chain amino acids glutamate, cysteine, phenylalanine, and histidine significantly increases BDSF levels (Fig. 2). All these amino acids had no effect on RpfF levels, suggesting that they are probably used as carbon sources to be involved in BDSF biosynthesis. Interestingly, these four non-branched chain amino acids are also abundant in the xylem fluid of Arabidopsis thaliana (Satoh 2006), soybean (Krishnan et al. 2011), wheat and barley (Goatley and Lewis 1966), and Petasites japonicus var. giganteus and Polygonum cuspidatum (Mizuno et al. 2002). However, very few branched-chained amino acids have been detected in the xylem fluids of these plants. Taken together, these findings suggest that $X$. campestris pv. campestris might use carbohydrates and non-branched chain amino acids found in the plant xylem as important nutrients to favor the synthesis of BDSF over that of DSF.

We also found that the addition of two $\alpha$-ketoacids, KIV and KIC, significantly increased DSF levels, and the addition of KMV increased IDSF levels (Fig. 4). This is highly consistent with the fact that these branched-chain $\alpha$-ketoacids are derived from the catabolism of leucine, valine, and isoleucine (Beck 2005). X. campestris pv. campestris encodes an $\alpha$-ketoacid dehydrogenase that converts them to acetyl-CoA primers for DSF and IDSF biosynthesis (Zhou et al. 2015). The shortchain carboxylic acids IBA, IVA, and 2MBA are also related to valine, leucine, and isoleucine (Ward et al. 1999). However, the addition of IBA, IVA, or 2MBA to XYS medium had little effect on BDSF, DSF, and IDSF levels. This is probably because either there is no suitable enzyme present in $X$. campestris pv. campestris to convert these compounds to acetyl-CoA primers or, alternatively, it is possible that $X$. campestris pv. campestris does not have a mechanism for the uptake of these carboxylic acids. Although the three $\alpha$-ketoacids tested do promote DSF and IDSF biosynthesis in cell culture, their endogenous levels in plants are extremely low; thus, their contribution to in-planta QS signal biosynthesis remains to be elucidated.

Plant hormones are chemicals that regulate essential plant processes such as seed development, flowering time and sex determination, leaf senescence, fruiting, and even plant death. Latest findings suggest that plant hormones not only steer plant immune responses but, also, may influence the virulence of the pathogen. For example, exogenous addition of SA to the opportunistic human pathogen Pseudomonas aeruginosa culture significantly reduced the production of motility, biofilm formation, and QS signal (Chow et al. 2011). Recently with the rice bacterial pathogen $X$. oryzae pv. oryzae, sodium salicylate (NaSA) induced a nearly 50\% increase in DSF levels (Xu et al. 2015). In this study, ABA and GA3 reduced BDSF levels and increased DSF levels (Fig. 5), while SA at a concentration of $0.1 \mathrm{mM}$ increased BDSF levels and decreased DSF levels (Fig. 5). SA and GA3 had little effect on $r p f F$ expression, while ABA significantly decreased RpfF levels. These findings suggest that $X$. campestris pv. campestris might use the plant hormones SA, $\mathrm{ABA}$, or GA3 as triggers to activate its virulence-associated QS signal biosynthesis. Since ABA and GA3 usually occur at extremely low concentrations in plants (Grennan 2006; Ren et al. 2007), their contributions to in-planta DSF family signal biosynthesis need to be further explored. SA is a phenolic phytohormone that occurs in plants as free SA, carboxylated esters, or phenolic glycosides. It is induced to relatively high levels 
upon pathogen invasion (Vlot et al. 2009). Our previous results showed that $X$. campestris pv. campestris cannot degrade SA in culture (Wang et al. 2015). The mechanism behind our observed effect of SA on the promotion of BDSF biosynthesis deserves further investigation.
Plants contain significant levels of aromatic metabolites. Many of them play essential roles in plant reproduction and growth as well as in defense against pathogens (Báidez et al. 2007). In response to pathogen attack, plants of the Brassicaceae family synthesize, de novo, a broad array of wide
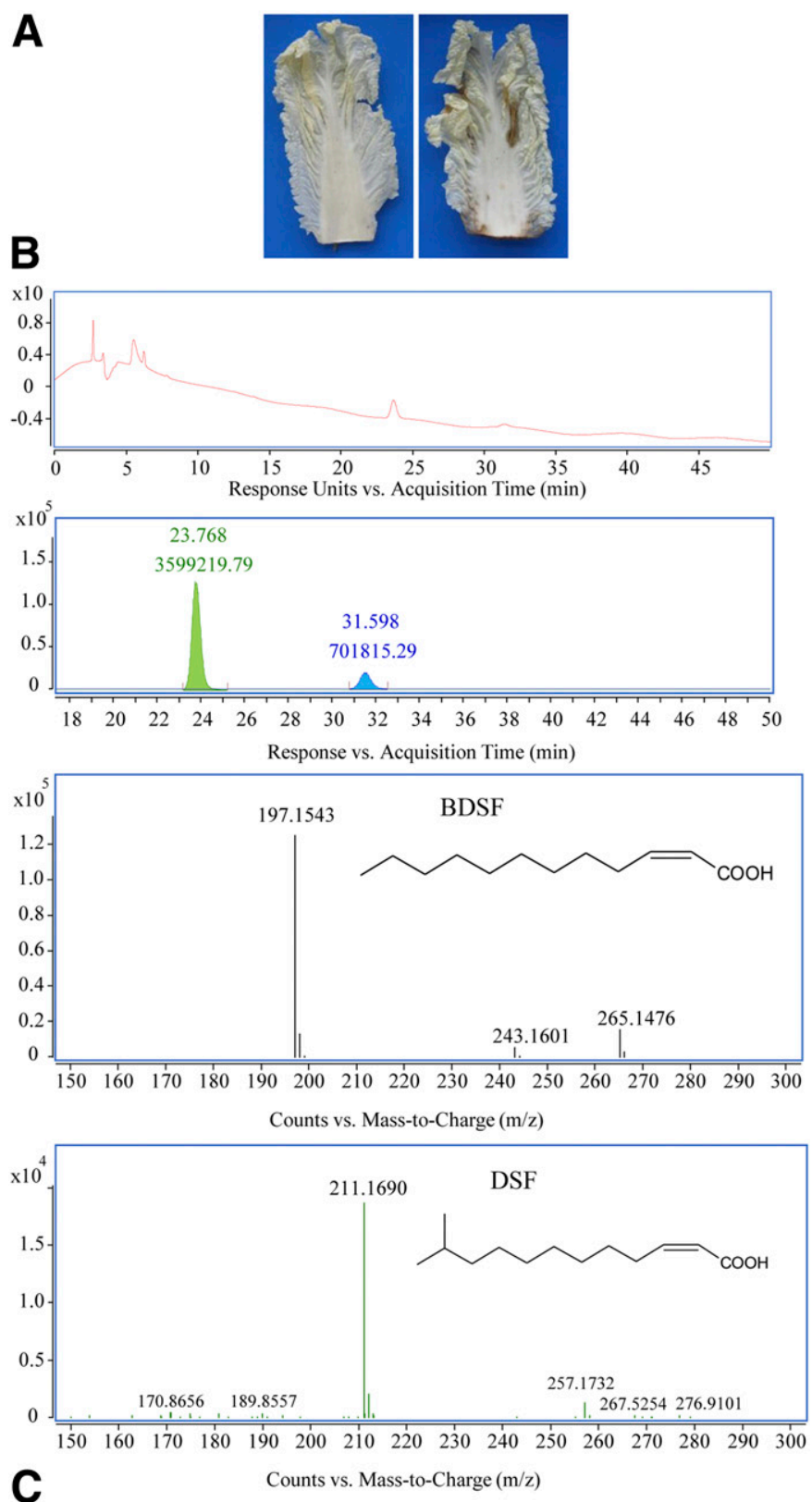

\begin{tabular}{|l|l|l|l|l|}
\hline Week & $\begin{array}{l}\text { Colony no. } \\
\text { /g F. W. }\end{array}$ & \multicolumn{2}{|c|}{ DSF-family signals detected } \\
\hline $1^{\text {st }}$ & $17.1 \pm 3.2$ & $\begin{array}{l}\text { Total Signals } \\
\text { (pmol/g F. W. })\end{array}$ & DSF & BDSF \\
\hline $2^{\text {nd }}$ & $65.4 \pm 5.7^{*}$ & $0.065 \pm 0.008^{*}$ & $\begin{array}{l}26.7 \% \pm \\
4.5 \%\end{array}$ & $\begin{array}{l}73.3 \% \pm \\
8.4 \%\end{array}$ \\
\hline $3^{\text {rd }}$ & $86.5 \pm 9.2^{* *}$ & $0.142 \pm 0.009^{* *}$ & $\begin{array}{l}\text { ND } \\
19.3 \% \pm\end{array}$ & $\begin{array}{l}80.7 \% \pm \\
4.0 \%\end{array}$ \\
\hline
\end{tabular}

Fig. 7. Identification of diffusible signal factor (DSF) family signals in infected Chinese cabbage. A, Xanthomonas campestris pv. campestris $\Delta$ rpfB-infected Chinese cabbage (right); left, Chinese cabbage inoculated with $1 \times$ phosphate buffered saline. B, Ultra-performance liquid chromatographic-time of flight-mass spectrometry analysis of the DSF family signals extracted from infected cabbage. C, The X. campestris pv. campestris colony number, total level of DSF family signals and ratios of DSF and BDSF in the infected tissues. Statistically significant differences with respect to data 1 week after inoculation are indicated by one or two asterisks $(P \leq 0.05$ or 0.01 , respectively). 
spectrum antimicrobial phenolics that accumulate rapidly at areas of pathogen infection (Abdel-Farid et al. 2007; Tan et al. 2004). X. campestris pv. campestris may also be exposed to high levels of natural phenolic compounds derived from cellwall degradation during infection. The degradative enzymes produced by $X$. campestris pv. campestris not only cleave the cell wall into simple sugars, but they also release lignin to form various types of aromatic compounds (Bertani et al. 2001). The presence of these phenolic metabolites may affect the biosynthesis of in-planta QS signals during X. campestris pv. campestris infection. In this study, we observed that the addition of 4-HBA or 2-HCA to X. campestris pv. campestris cultures significantly increased BDSF levels, and the addition of 3-HBA significantly decreased DSF levels (Fig. 6). In
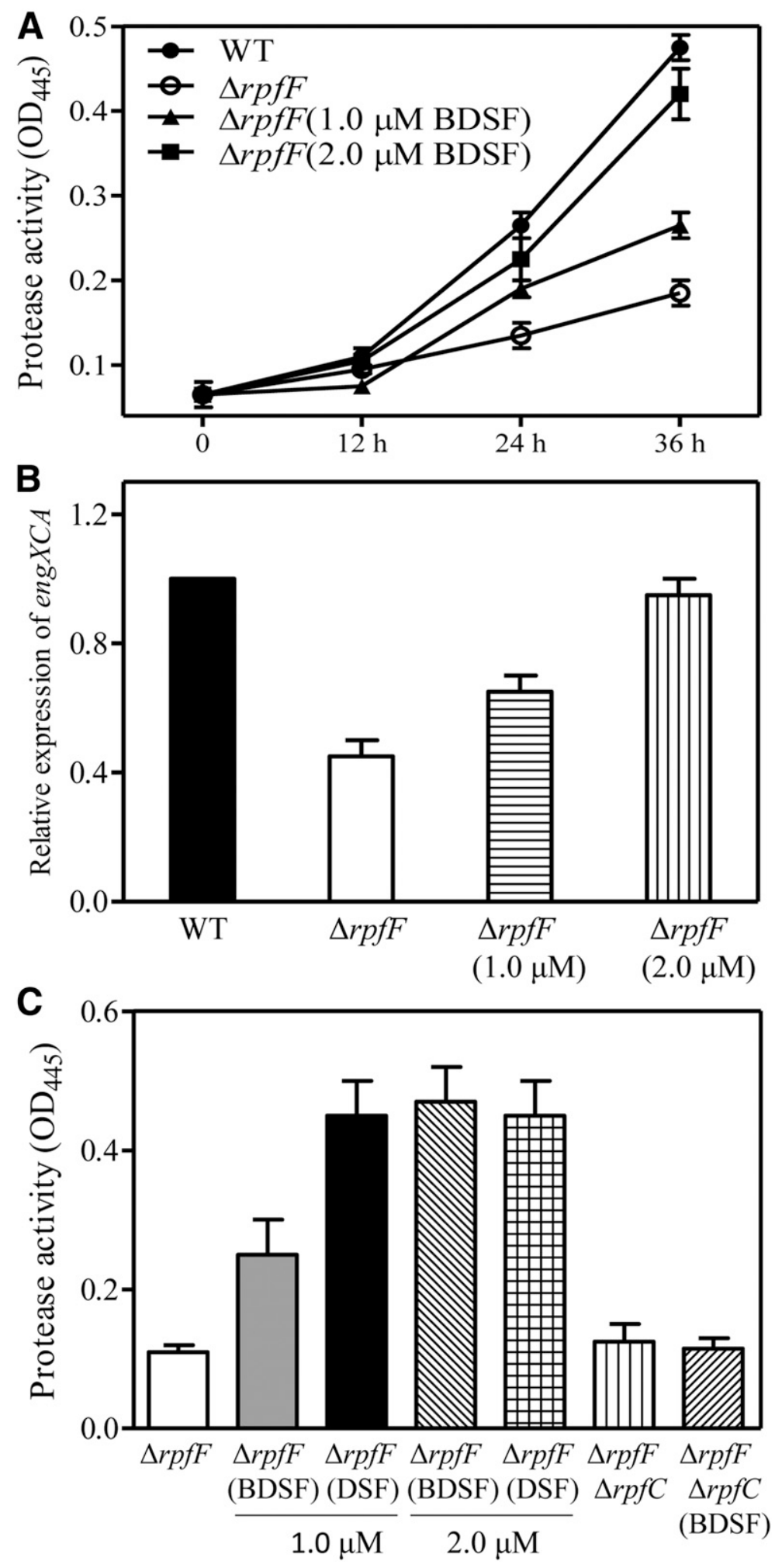

Fig. 8. Diffusible signal factor BDSF is active in the induction of protease activity and endoglucanase gene expression. A, The effects of BDSF on protease activity of the $r p f F$ mutant. B, The effects of BDSF on the expression of engXCA. C, A comparison of the inductive effects of diffusible signal factor (DSF) and BDSF at concentrations of either 1.0 or $2.0 \mu \mathrm{M}$ on protease activity. Data are shown as means \pm one standard deviation of three independent assays. 
X. campestris pv. campestris, 3-HBA and 4-HBA were previously shown to be involved in the yellow pigment xanthomonadin and coenzyme Q8 biosynthesis, respectively (He et al. 2011; Zhou et al. 2013). DSF family signals, CoQ8, and xanthomonadin all compete for the same primer intermediate acylACP in their biosynthetic pathways (Zhou et al. 2015). The addition of 3-HBA promotes xanthomonadin biosynthesis, resulting in less acyl-ACP available for DSF or BDSF biosynthesis. This is probably why high concentrations of 3-HBA repressed DSF biosynthesis. $X$. campestris pv. campestris contains a $p c a$ gene cluster for the efficient degradation of 4HBA into PCA, which is further converted into acetyl CoA through the tricarboxylic acid cycle (Wang et al. 2015). The resulting acetyl $\mathrm{CoA}$ could be used as a building block for BDSF biosynthesis (Zhou et al. 2015), and this is probably why high concentrations of 4-HBA induced BDSF biosynthesis (Fig. 6). The present study showed that 2-HCA promotes BDSF biosynthesis through increasing RpfF protein levels (Fig. 6). 2HCA is a derivative of cinnamic acid, which is obtained from the oil of cinnamon, and hydroxycinnamic acid derivatives reportedly have antioxidant activity (Taubert et al. 2003). In addition, some phenolic compounds apparently act as signaling molecules in plant-microbe interactions. For instance, phenolic compounds strongly regulate nod gene expression and modify the legume-rhizobial symbiosis in Rhizobium spp. (Schultze and Kondorosi 1998). Thus, the mechanism by which 2-HCA regulates $r p f F$ expression deserves further investigation.

\section{BDSF is a major in-planta QS signal during infection.}

All the DSF family signals characterized from $X$. campestris pv. campestris to date were derived from in-vitro cell cultures. Evidence from the present study suggests that BDSF should be the predominant in-planta QS signal in X. campestris pv. campestris infection and pathogenesis in host plants. Deng et al. (2015) found that the addition of crucifer plant extract significantly increased DSF family signal production in $X$. campestris pv. campestris, and the yield of DSF was substantially higher than that of BDSF or DSF-II. The discrepancy between both studies is probably due to the different media used. The results by Deng et al. (2015) were obtained in rich medium. As we have shown that DSF levels are much higher than BDSF levels when $X$. campestris pv. campestris was grown in rich nutrient agar and Luria Bertani medium, because these media contain high levels of branched amino acids and related carboxylic acids (Zhou et al. 2015). The media XY or XYS used in this study are relatively poor and close to the growth conditions that $X$. campestris pv. campestris may encounter during infection.

Previous studies showed that $X$. oryzae pv. oryzae, $X$. campestris pv. campestris, and Burkholderia sp. produce multiple DSF family signals (Deng et al. 2010; He et al. 2010; Zhou et al. 2015). The relative proportions of these signals are influenced by culture medium composition. DSF is the dominant signal produced by $X$. campestris pv. campestris in nutrient-rich yeast extract broth medium, whereas BDSF is the dominant one in nutrient-poor XOLN medium (Zhou et al. 2015). The plant environment is poor in nutrients and the xylem fluid mainly contains carbohydrates, inorganic ions, and organic substances such as amino acids (Satoh 2006). The present study further confirmed that several plant-derived compounds promote BDSF biosynthesis. Thus, the predomination of BDSF over DSF in the infected tissues should be a consequence of nutrient availability. However, we could not rule out other inplanta factors that might affect DSF family molecule preference, since there is still a significant level of DSF (19.3 to about $26.7 \%$ of the total) present in the infected cabbage tissues (Fig. 7). This study, therefore, does not rule out the possibility that
DSF also plays a role in $X$. campestris pv. campestris pathogenesis in Chinese cabbage. Further insights into this point will be gained from the experimental analysis of the physiological concentration of both DSF and BDSF in the infected tissues and a more thorough analysis of the differential effect of BDSF and DSF on the expression of various QS-dependent genes in $X$. campestris pv. campestris.

DSF and BDSF at higher concentrations $(\geq 2 \mu \mathrm{M})$ displayed similar effects on engXCA expression and protease activity in vitro; however, DSF is more active than BDSF at lower concentrations $(\leq 1 \mu \mathrm{M})$ (Fig. 7). Since both signals induce engXCA expression and protease activity through the receptor RpfC (Fig. 8), DSF probably has higher affinity to RpfC than BDSF. This needs to be further investigated. To our knowledge, this study represents the first report directly showing the inplanta production of a pathogen QS signal. These findings are also consistent with several other reports showing that the major DSF family signals produced by Burkholderia species, Xylella fastidiosa, and Pseudomonas aeruginosa are the straight-chained fatty acids, cis-2-dodecenoic acid, tetradecenoic acid, or cis-2-decenoic acid, respectively (Beaulieu et al. 2013; Davies and Marques 2009; Deng et al. 2010). The identification of BDSF as the dominant in-planta QS signal provides not only a better understanding of the molecular interactions between Xanthomonas spp. and crucifer host plants but also suggests BDSF as the logical target for the design of strategies to interrupt $X$. campestris pv. campestris signaling during infection.

In this study, the strains $\Delta r p f C \Delta r p f B$ and $\Delta r p f B$, respectively, were used to monitor the DSF family signals produced in culture and in the infected cabbage tissue. However, actual situations with the wild-type strain in planta may be different. First, since RpfB has been shown earlier to have high homology to fatty acid metabolism enzyme FadD (Zhou et al. 2015), it could also alter the balance of free fatty acid present in the strain. These mutants themselves may have an effect on growth, virulence, and even signal production. Second, previous studies in Xanthomonas spp. and other closely related bacteria have shown that the secreted signals can be modified (Zhou et al. 2017). It is also possible that the DSF signals produced in planta by these mutant strains are modified by the plant enzymes or microbial enzymes that are associated with endophytes. Collectively, in the actual situation during wild-type colonization, predominant DSF signal production and response might be different from what we deduced in this study. Further studies are needed to get an exact idea about the DSF production dynamics inside the plant.

\section{MATERIALS AND METHODS}

\section{Bacterial strains and growth conditions.}

$X$. campestris pv. campestris wild-type strain $X C 1$ and their derivatives were described previously (He et al. 2006b). Medium and bacterial strains used in the present study are listed in Supplementary Table S1.X. campestris pv. campestris strains were grown at $30^{\circ} \mathrm{C}$ in media with $25 \mu \mathrm{g}$ of rifampicin per milliliter. For media preparation, tryptone, peptone, yeast extract, sucrose, amino acids, $\alpha$-keto acids, carboxylic acids, phenolic acids, organic acids, and plant hormones were purchased from Sangon Biotech (Shanghai, China). Bacterial growth was determined by measuring $\mathrm{OD}_{600}$.

\section{Extraction, purification, and quantitative analysis of DSF family signals}

in $X$. campestris pv. campestris culture supernatant.

Extraction and purification of DSF family signals in $X$. campestris pv. campestris culture supernatants were 
performed as previously described (He et al. 2010). Briefly, $X$. campestris pv. campestris strains were grown for $24 \mathrm{~h}$ and, then, $20 \mathrm{ml}$ of supernatant was collected by centrifugation at 3,800 rpm for $30 \mathrm{~min}$ (Heraeus Multifuge x1R, Thermo Scientific). The $\mathrm{pH}$ of the supernatants was adjusted to 4.0. An equal volume of ethyl acetate was then added to the supernatant for extraction for 30 mins. Ethyl acetate fractions were collected, and the solvent was removed by rotary evaporation. The residues were dissolved in $1 \mathrm{ml}$ of methanol. The crude extract was then subjected to a $0.45 \mathrm{~m}$ Minisart filter unit and the collected filtrate was condensed to $0.5 \mathrm{ml}$. Extract $(3 \mu \mathrm{l})$ was then subjected to high-performance liquid chromatography with a C18 reverse-phase column $(4.6150 \mathrm{~mm}$; Agilent) and was eluted with water in methanol (23:77, vol/vol, $0.1 \%$ formic acid) at a flow rate of $1 \mathrm{ml} / \mathrm{min}$ in an Agilent Technologies 1260 Infinity system with DAD G1315D VL detector.

\section{Protein extraction and Western blotting analysis of RpfF expression level.}

$X$. campestris pv. campestris cultures were collected by centrifugation at $12,000 \mathrm{rpm}$ for $10 \mathrm{~min}$ at $4^{\circ} \mathrm{C}$. The pellets were resuspended in $200 \mu \mathrm{l}$ of bacterial protein extraction mixture composed of $1 \mathrm{ml}$ of EasyLys bacterial protein extraction solution (Thermo Scientific), $2 \mu \mathrm{l}$ of lysozyme, and $2 \mu \mathrm{l}$ of DNase I. The protein extract was kept at room temperature for $10 \mathrm{~min}$ and was then centrifugated at $12,000 \mathrm{rpm}$ for $10 \mathrm{~min}$ at $4{ }^{\circ} \mathrm{C}$. Supernatant $(100 \mu \mathrm{l})$ was transferred into a clean Eppendorf tube. Protein concentration was determined by spectrophotometer at $\mathrm{OD}_{595}$. Western blotting analysis was performed as described by Green and Sambrook (2012). The blocked membrane was incubated with primary polyclonal anti-RpfF serum (Zhou et al. 2015) for $4 \mathrm{~h}$ at room temperature. After washing with a $0.05 \%$ Tween-20-containing PBS buffer, the blots were incubated with the secondary goat anti-rabbit immunoglobulin $\mathrm{G}(\mathrm{H}+\mathrm{L})$-horseradish peroxidase conjugate (Bio-Rad). The hybridization signal was detected using the Super Signal West Pico chemiluminescent substrate (Pierce).

\section{Preparation of Chinese cabbage hydrolysate samples.}

Hydrolyzed Chinese cabbage samples were prepared as previously described with modifications (Xu et al. 2010). Chinese cabbage leaves ( $300 \mathrm{~g}$ ) were chopped and blended with $300 \mathrm{ml}$ of water for $15 \mathrm{~min}$. The sample was pretreated with $\mathrm{NaOH}(1 \% \mathrm{wt} / \mathrm{vol})$ at a ratio $1: 10$ for $15 \mathrm{~min}$ in an autoclave. The solids were removed using a filtration cloth. The filtrate was then centrifuged at $16,000 \times g$ for $10 \mathrm{~min}$, to remove any insoluble particles, and was adjusted to 7.0. The extract was condensed to $100 \mathrm{ml}$ on a rotary evaporator (Eyela, Tokyo Rikakikai Co.) at $40^{\circ} \mathrm{C}$.

\section{Infection of Chinese cabbage}

by the $X$. campestris pv. campestris rpfB mutant.

$X$. campestris pv. campestris rpfB mutant strain was grown, overnight, in XYS medium. The bacterial cells were then collected by centrifugation and were resuspended into XYS medium to an $\mathrm{OD}_{600}$ of 0.1 . Fully matured Chinese cabbage (Wongbok) leaves were used for infection. The bottom part (about $1 \mathrm{~cm}$ ) of each leaf was cut off, and the resulting wound was immediately immersed in the above-mentioned bacterial suspension in a beaker. The cabbage and beaker were then transferred to a glass desiccator (Isolab) that was connected to a nitrogen cylinder. The leaves were subjected to a 5 -atmospheric pressure $\left(5 \times 10^{5} \mathrm{~Pa}\right)$ for $10 \mathrm{~min}$ to promote $X$. campestris pv. campestris to get entry into the vascular system of the cabbage leaf. The treated leaves were then transferred into a tray with wet filter papers. The tray was wrapped with plastic film and kept in an incubator at $25^{\circ} \mathrm{C}$ with $80 \%$ humidity for a week. The bottom part (about $3 \mathrm{~cm}$ ) of each leaf was removed for DSF extraction and colony counting. For each treatment, 10 pieces of leaves were used and two independent experiments were performed.

Extraction and ultra-performance liquid chromatographic-time of flight-mass spectrometry (UPLC-TOF-MS) analysis of DSF family signals in the infected cabbage.

To extract DSF family signals produced by X. campestris pv. campestris inside infected Chinese cabbage, $500 \mathrm{~g}$ of infected leaves were collected, were cut into small pieces, and were then blended with $200 \mathrm{ml}$ of sterile water in an electric juicer (HR2168/40, Philips) for $10 \mathrm{~min}$. The mixture was adjusted to a $\mathrm{pH}$ of 4.0 , using hydrochloric acid $(5 \mathrm{~N})$. The mixture was then transferred to a 5-liter flask with $500 \mathrm{ml}$ of ethyl acetate and was extracted for $30 \mathrm{~min}$ by shaking at $200 \mathrm{rpm}$ at room temperature. The ethyl acetate fractions were collected by centrifugation at $10,000 \mathrm{rpm}$ for $10 \mathrm{~min}$, and the solvent was removed by rotary evaporation to dryness. The resulting residue was dissolved in $2 \mathrm{ml}$ of methanol and was subjected to flash column chromatography, using a silica gel column $(12 \times 150 \mathrm{~mm}$, Biotage Flash 12M cartridge), and finally, was eluted with ethyl acetate-hexane $(25: 75, \mathrm{vol} / \mathrm{vol}, 0.05 \%$ acetic acid). The collected active component was condensed and applied to UPLCTOF-MS (Agilent) for further analysis.

Detection and quantitative analysis of DSF and BDSF from the extract were conducted following the recently published protocol (Zhou et al. 2018). Briefly, $5 \mu$ l of the collected samples was applied to an UPLC system (Agilent 1290 Infinity, Agilent Technologies) on a Zorbax XDB C18 reverse phase column $(4.6 \times 150 \mathrm{~mm}, 5 \mu \mathrm{m}$, Agilent Technologies) and was eluted with methanol-water $(80: 20, \mathrm{vol} / \mathrm{vol})$ at a flow rate of $0.4 \mathrm{ml} / \mathrm{min}$. LC elute was coupled to an accurate mass TOF MS (Agilent TOF MS 6230, Agilent Technologies) equipped with an Agilent Jet Stream electrospray ionization source. The mass spectrometer was operated in the negative ion mode. Nitrogen was used for drying ( 8 liters per minute, $\left.325^{\circ} \mathrm{C}\right)$, sheath $(11$ liters per minute, $350^{\circ} \mathrm{C}$ ), and nebulizer gas (35 psi). To quantify the BDSF and DSF concentration in the sample, a standard curve for DSF or BDSF by plotting the peak area vs. the known concentrations $(1,5,10$, and $50 \mu \mathrm{M})$. The concentration of DSF and BDSF in the extract is calculated as described by Zhou et al. (2018).

\section{Quantitative determination of protease activity and quantitative real-time polymerase chain reaction (PCR) analysis of the engXCA mRNA level in $X$. campestris pv. campestris culture.}

The extracellular protease activity in culture supernatants was quantitatively analyzed according to the method previously described by Swift et al. (1999). For quantitative real-time PCR analysis, total RNAs were isolated using the RNeasy mini-prep kit (Qiagen). The PrimeScript RT reagent kit was used for quantitative reverse transcription PCR analysis. The primer set designed from a engXCA full DNA sequence were as follows: Eng-FOR, TTCAACGACAGCAACTTCCC; Eng-REV, GACC AGTAGAAGCCCTGGTT. Quantification of gene expression and melting curve analysis were performed using Mastercycler ep Realplex 4S (Eppendorf) and SYBR Premix Ex Taq (Takara). The 16S rRNA gene was used as a reference to standardize all the samples and replicates. For protease activity and engXCA level analyses, the strain was grown in XYS medium at $28^{\circ} \mathrm{C}$ with shaking at $200 \mathrm{rpm}$ for $24 \mathrm{~h}$.

\section{Statistical analysis.}

Analysis of variance for experimental datasets was performed using GraphPad prism software version 5.0 (GraphPad 
software Inc.). Significant effects of different treatments were determined by the $F$ value $(P=0.05)$. Each experiment was repeated twice, and the data was shown as mean with one standard deviation.

\section{ACKNOWLEDGMENTS}

We thank W. Lin for providing some plant hormones.

\section{LITERATURE CITED}

Abdel-Farid, I. B., Kim, H. K., Choi, Y. H., and Verpoorte, R. 2007. Metabolic characterization of Brassica rapa leaves by NMR spectroscopy. J. Agric. Food Chem. 55:7936-7943.

Akimoto-Tomiyama, C., Furutani, A., and Ochiai, H. 2014. Real time live imaging of phytopathogenic bacteria Xanthomonas campestris pv. campestris MAFF106712 in 'plant sweet home'. PLoS One 9: e94386.

Báidez, A. G., Gómez, P., Del Río, J. A., and Ortuño, A. 2007 Dysfunctionality of the xylem in Olea europaea L. plants associated with the infection process by Verticillium dahliae Kleb. Role of phenolic compounds in plant defense mechanism. J. Agric. Food Chem. 55: 3373-3377.

Beaulieu, E. D., Ionescu, M., Chatterjee, S., Yokota, K., Trauner, D., and Lindow, S. 2013. Characterization of a diffusible signaling factor from Xylella fastidiosa. MBio 4:e00539-e12.

Beck, H. C. 2005. Branched-chain fatty acid biosynthesis in a branchedchain amino acid aminotransferase mutant of Staphylococcus carnosus. FEMS Microbiol. Lett. 243:37-44.

Bertani, I., Kojic, M., and Venturi, V. 2001. Regulation of the p-hydroxybenzoic acid hydroxylase gene (pobA) in plant-growth-promoting Pseudomonas putida WCS358. Microbiology 147:1611-1620.

Cai, Z., Yuan, Z. H., Zhang, H., Pan, Y., Wu, Y., Tian, X. Q., Wang, F. F., Wang, L., and Qian, W. 2017. Fatty acid DSF binds and allosterically activates histidine kinase RpfC of phytopathogenic bacterium Xanthomonas campestris pv. campestris to regulate quorum-sensing and virulence. PLoS Pathog. 13:e1006304.

Cheng, Z., He, Y. W., Lim, S. C., Qamra, R., Walsh, M. A., Zhang, L. H., and Song, H. 2010. Structural basis of the sensor-synthase interaction in autoinduction of the quorum sensing signal DSF biosynthesis. Structure 18:1199-1209.

Chow, S., Gu, K., Jiang, L., and Nassour, A. 2011. Salicylic acid affects swimming, twitching and swarming motility in Pseudomonas aeruginosa, resulting in decreased biofilm formation. J. Experim. Microbiol. Immunol. 15:22-29.

Davies, D. G., and Marques, C. N. 2009. A fatty acid messenger is responsible for inducing dispersion in microbial biofilms. J. Bacteriol. 191:1393-1403.

Dean, S. N., Chung, M. C., and van Hoek, M. L. 2015. Burkholderia diffusible signal factor signals to Francisella novicida to disperse biofilm and increase siderophore production. Appl. Environ. Microbiol. 81:7057-7066.

Deng, Y., Liu, X., Wu, J., Lee, J., Chen, S., Cheng, Y., Zhang, C., and Zhang, L. H. 2015. The host plant metabolite glucose is the precursor of diffusible signal factor (DSF) family signals in Xanthomonas campestris. Appl. Environ. Microbiol. 81:2861-2868.

Deng, Y., Wu, J., Eberl, L., and Zhang, L. H. 2010. Structural and functional characterization of diffusible signal factor family quorum-sensing signals produced by members of the Burkholderia cepacia complex. Appl. Environ. Microbiol. 76:4675-4683.

Deng, Y., Wu, J., Tao, F., and Zhang, L. H. 2011. Listening to a new language: DSF-based quorum sensing in gram-negative bacteria. Chem. Rev. 111:160-173.

Deng, Y., Wu, J., Yin, W., Li, P., Zhou, J., Chen, S., He, F., Cai, J., and Zhang, L. H. 2016. Diffusible signal factor family signals provide a fitness advantage to Xanthomonas campestris pv. campestris in interspecies competition. Environ. Microbiol. 18:1534-1545.

Goatley, J. L., and Lewis, R. W. 1966. Composition of guttation fluid from rye, wheat, and barley seedlings. Plant Physiol. 41:373-375.

Green, M. R., and Sambrook, J. R. 2012. Molecular Cloning: A Laboratory Manual, 4th Ed. Cold Spring Harbor Laboratory Press, New York.

Grennan, A. K. 2006. Gibberellin metabolism enzymes in rice. Plant Physiol. 141:524-526.

Han, Y., Wang, Y., Tombosa, S., Wright, S., Huffman, J., Yuen, G., Qian, G., Liu, F., Shen, Y., and Du, L. 2015. Identification of a small molecule signaling factor that regulates the biosynthesis of the antifungal polycyclic tetramate macrolactam HSAF in Lysobacter enzymogenes. Appl. Microbiol. Biotechnol. 99:801-811.

He, Y. W., Ng, A. Y., Xu, M., Lin, K., Wang, L. H., Dong, Y. H., and Zhang, L. H. 2007. Xanthomonas campestris cell-cell communication involves a putative nucleotide receptor protein Clp and a hierarchical signalling network. Mol. Microbiol. 64:281-292.

He, Y. W., Wang, C., Zhou, L., Song, H., Dow, J. M., and Zhang, L. H. 2006a. Dual signaling functions of the hybrid sensor kinase RpfC of Xanthomonas campestris involve either phosphorelay or receiver domain-protein interaction. J. Biol. Chem. 281:33414-33421.

He, Y. W., Wu, J., Cha, J. S., and Zhang, L. H. 2010. Rice bacterial blight pathogen Xanthomonas oryzae pv. oryzae produces multiple DSF-family signals in regulation of virulence factor production. BMC Microbiol. 10: 187-196.

He, Y. W., Wu, J., Zhou, L., Yang, F., He, Y. Q., Jiang, B. L., Bai, L., Xu, Y. Deng, Z., Tang, J. L., and Zhang, L. H. 2011. Xanthomonas campestris diffusible factor is 3-hydroxybenzoic acid and is associated with xanthomonadin biosynthesis, cell viability, antioxidant activity, and systemic invasion. Mol. Plant-Microbe Interact 24:948-957.

He, Y. W., Xu, M., Lin, K., Ng, Y. J., Wen, C. M., Wang, L. H., Liu, Z. D., Zhang, H. B., Dong, Y. H., Dow, J. M., and Zhang, L. H. 2006b. Genome scale analysis of diffusible signal factor regulon in Xanthomonas campestris pv. campestris: Identification of novel cell-cell communication-dependent genes and functions. Mol. Microbiol. 59:610-622.

He, Y. W., and Zhang, L. H. 2008. Quorum sensing and virulence regulation in Xanthomonas campestris. FEMS Microbiol. Rev. 32:842-857.

Hildebrandt, T. M., Nunes Nesi, A., Araújo, W. L., and Braun, H. P. 2015. Amino acid catabolism in plants. Mol. Plant 8:1563-1579.

Hu, Z., Dong, H., Ma, J. C., Yu, Y., Li, K. H., Guo, Q. Q., Zhang, C., Zhang, W. B., Cao, X., Cronan, J. E., and Wang, H. 2018. Nove Xanthomonas campestris long-chain-specific 3-oxoacyl-acyl carrier protein reductase involved in diffusible signal factor synthesis. MBio 9:e00596-18

Huang, W. Y., Cai, Y. Z., and Zhang, Y. 2010. Natural phenolic compounds from medicinal herbs and dietary plants: Potential use for cancer prevention. Nutr. Cancer 62:1-20.

Hugouvieux, V., Barber, C. E., and Daniels, M. J. 1998. Entry of Xanthomonas campestris pv. campestris into hydathodes of Arabidopsis thaliana leaves: A system for studying early infection events in bacterial pathogenesis. Mol. Plant-Microbe Interact 11:537-543.

Kakkar, A., Nizampatnam, N. R., Kondreddy, A., Pradhan, B. B., and Chatterjee, S. 2015. Xanthomonas campestris cell-cell signalling molecule DSF (diffusible signal factor) elicits innate immunity in plants and is suppressed by the exopolysaccharide xanthan. J. Exp. Bot. 66 6697-6714.

Kaneda, T. 1991. Iso- and anteiso-fatty acids in bacteria: Biosynthesis, function, and taxonomic significance. Microbiol. Rev. 55:288-302.

Krishnan, H. B., Natarajan, S. S., Bennett, J. O., and Sicher, R. C. 2011 Protein and metabolite composition of xylem sap from field-grown soybeans (Glycine max). Planta 233:921-931.

Kumar, V., Sharma, A., Kaur, R., Thukral, A. K., Bhardwaj, R., and Ahmad, P. 2017. Differential distribution of amino acids in plants. Amino Acids 49:821-869.

Mizuno, N., Takahashi, A., Wagatsuma, T., Mizuno, T., and Obata, H. 2002. Chemical composition of guttation fluid and leaves of Petasites japonicus v. giganteus and Polygonum cuspidatum growing on ultramafic soil. Soil Sci. Plant Nutr. 48:451-453.

Onsando, J. M. 1992. Black rot of crucifers. Pages 243-252 in: Diseases of Vegetables and Oil Seed Crops. H. S. Chaube, J. Kumar, A. N. Mukhopadhyay, and U. S. Singh, eds. Prentice-Hall, Englewood Cliffs.

Ren, Y. F., He, J. Y., and Wang, X. F. 2007. Changes in activities of three enzymes degrading galactomannan during and following rice seed germination. Rice Sci. 14:295-301.

Satoh, S. 2006. Organic substances in xylem sap delivered to above-ground organs by the roots. J. Plant Res. 119:179-187.

Schultze, M., and Kondorosi, A. 1998. Regulation of symbiotic root nodule development. Annu. Rev. Genet. 32:33-57.

Slater, H., Alvarez-Morales, A., Barber, C. E., Daniels, M. J., and Dow, J. M. 2000. A two-component system involving an HD-GYP domain protein links cell-cell signalling to pathogenicity gene expression in Xanthomonas campestris. Mol. Microbiol. 38:986-1003.

Swift, S., Lynch, M. J., Fish, L., Kirke, D. F., Tomás, J. M., Stewart, G. S., and Williams, P. 1999. Quorum sensing-dependent regulation and blockade of exoprotease production in Aeromonas hydrophila. Infect. Immun. 67:5192-5199.

Tan, J., Bednarek, P., Liu, J., Schneider, B., Svatoš, A., and Hahlbrock, K. 2004. Universally occurring phenylpropanoid and species-specific 
indolic metabolites in infected and uninfected Arabidopsis thaliana roots and leaves. Phytochemistry 65:691-699.

Tang, J. L., Liu, Y. N., Barber, C. E., Dow, J. M., Wootton, J. C., and Daniels, M. J. 1991. Genetic and molecular analysis of a cluster of $r p f$ genes involved in positive regulation of synthesis of extracellular enzymes and polysaccharide in Xanthomonas campestris pathovar campestris. Mol. Gen. Genet. 226:409-417.

Tao, F., He, Y. W., Wu, D. H., Swarup, S., and Zhang, L. H. 2010. The cyclic nucleotide monophosphate domain of Xanthomonas campestris global regulator Clp defines a new class of cyclic di-GMP effectors. J. Bacteriol. 192:1020-1029.

Taubert, D., Breitenbach, T., Lazar, A., Censarek, P., Harlfinger, S., Berkels, R., Klaus, W., and Roesen, R. 2003. Reaction rate constants of superoxide scavenging by plant antioxidants. Free Radic. Biol. Med. 35:1599-1607.

Vlot, A. C., Dempsey, D. A., and Klessig, D. F. 2009. Salicylic acid, a multifaceted hormone to combat disease. Annu. Rev. Phytopathol. 47: 177-206.

Wang, L. H., He, Y., Gao, Y., Wu, J. E., Dong, Y. H., He, C., Wang, S. X., Weng, L. X., Xu, J. L., Tay, L., Fang, R. X., and Zhang, L. H. 2004. A bacterial cell-cell communication signal with cross-kingdom structural analogues. Mol. Microbiol. 51:903-912.

Wang, P., Du, Y., Hou, Y. J., Zhao, Y., Hsu, C. C., Yuan, F., Zhu, X., Tao, W. A., Song, C. P., and Zhu, J. K. 2015. Nitric oxide negatively regulates abscisic acid signaling in guard cells by S-nitrosylation of OST1. Proc. Natl. Acad. Sci. U.S.A. 112:613-618.

Wang, X. Y., Zhou, L., Yang, J., Ji, G. H., and He, Y. W. 2016. The RpfBdependent quorum sensing signal turnover system is required for adaptation and virulence in rice bacterial blight pathogen Xanthomonas oryzae pv. oryzae. Mol. Plant-Microbe Interact 29:220-230.
Ward, D. E., Ross, R. P., van der Weijden, C. C., Snoep, J. L., and Claiborne, A. 1999. Catabolism of branched-chain $\alpha$-keto acids in Enterococcus faecalis: The bkd gene cluster, enzymes, and metabolic route. J. Bacteriol. 181:5433-5442.

Williams, P. H. 1980. Black rot: A continuing threat to world crucifers. Plant Dis. 64:736-742.

Xu, J., Cheng, J. J., Sharma-Shivappa, R. R., and Burns, J. C. 2010. Sodium hydroxide pretreatment of switchgrass for ethanol production. Energy Fuels 24:2113-2119.

Xu, J., Zhou, L., Venturi, V., He, Y. W., Kojima, M., Sakakibari, H., Höfte, M., and De Vleesschauwer, D. 2015. Phytohormone-mediated interkingdom signaling shapes the outcome of rice-Xanthomonas oryzae pv. oryzae interactions. BMC Plant Biol. 15:10.

Zhou, L., Huang, T. W., Wang, J. Y., Sun, S., Chen, G., Poplawsky, A., and He, Y. W. 2013. The rice bacterial pathogen Xanthomonas oryzae pv. oryzae produces 3-hydroxybenzoic acid and 4-hydroxybenzoic acid via XanB2 for use in xanthomonadin, ubiquinone, and exopolysaccharide biosynthesis. Mol. Plant-Microbe Interact 26:1239-1248.

Zhou, L., Sun, S., Zhang, W., and He, Y. W. 2018. Ultra-performance liquid chromatography/mass spectrometry for the detection and quantification of diffusible signal factor (DSF) family quorum-sensing signals. Methods Mol. Biol. 1673:97-105.

Zhou, L., Yu, Y., Chen, X., Diab, A. A., Ruan, L., He, J., Wang, H., and He, Y. W. 2015. The multiple DSF-family QS signals are synthesized from carbohydrate and branched-chain amino acids via the FAS elongation cycle. Sci. Rep. 5:13294.

Zhou, L., Zhang, L. H., Cámara, M., and He, Y. W. 2017. The DSF family of quorum sensing signals: Diversity, biosynthesis, and turnover. Trends Microbiol. 25:293-303. 